\title{
Evaluation of the Properties of Cellulose Ester Films that Incorporate Essential Oils
}

\author{
Atanu Biswas $\mathbb{D}^{1}{ }^{1}$ Maria do Socorro Rocha Bastos, ${ }^{2}$ Roselayne Ferro Furtado, ${ }^{2}$ \\ Gary Kuzniar, ${ }^{1}$ Veera Boddu $\left(\mathbb{D},{ }^{1}\right.$ and H. N. Cheng ${ }^{3}{ }^{3}$ \\ ${ }^{1}$ National Center for Agricultural Utilization Research, USDA Agricultural Research Service, 1815 N. University St., Peoria, \\ IL 61604, USA \\ ${ }^{2}$ Embrapa Agroindústria Tropical, Dra. Sara Mesquita, 2270, 60511-110, Planalto Pici, Fortaleza, Ceará, Brazil \\ ${ }^{3}$ Southern Regional Research Center, USDA Agricultural Research Service, 1100 Robert E. Lee Blvd., New Orleans, LA 70124, USA \\ Correspondence should be addressed to Atanu Biswas; atanu.biswas@usda.gov and H. N. Cheng; hn.cheng@ars.usda.gov
}

Received 5 February 2020; Accepted 2 March 2020; Published 21 May 2020

Guest Editor: Pei-Yu Kuo

Copyright (C) 2020 Atanu Biswas et al. This is an open access article distributed under the Creative Commons Attribution License, which permits unrestricted use, distribution, and reproduction in any medium, provided the original work is properly cited.

Films made from cellulose esters are often used as bio-based food packaging materials. In this work, we studied the incorporation of nine essential oils into cellulose acetate, cellulose acetate propionate, and cellulose acetate butyrate. The essential oils were derived from lime, nutmeg, eugenol, pimenta berry, rosemary, petitgrain, coffee, anise, and trans-cinnamaldehyde. In almost all cases, the addition of essential oils to cellulose ester reduced tensile strength and Young's modulus but increased elongation at break. Thus, an essential oil acted like a plasticizer that enhanced the flexibility of the polymer. Essential oils containing limonene and pinenes (e.g., from lime and nutmeg) gave the strongest plasticizing action, whereas essentials oils containing fatty acids (e.g., from coffee) were the weakest plasticizers. The water barrier property was improved the most when essential oils were added to cellulose acetate; however, different cellulose ester/essential oil combinations showed different effects. Whereas most of the essential oils decreased the transparency of the films, eugenol, pimento berry, and anise were notable exceptions. Thus, depending on a specific application, a particular polymer/EO combination can be used to give the optimal performance.

\section{Introduction}

Many polymeric packaging materials have been commercialized successfully to increase the shelf-lives of fruits and vegetables on supermarkets and minimize food spoilage $[1,2]$. However, most of these polymers are derived from petroleum-based raw materials, and their increased consumption can produce large amounts of plastic wastes and cause disposal and environmental problems $[3,4]$. A solution to this problem is to use agro-based biodegradable packaging film [5-7]. Thus, there is current interest to explore polysaccharides and their derivatives as food coatings, wrappings, and packaging $[8,9]$. For this application, cellulose esters are particularly advantageous. They have been known and manufactured for many years, possess good film properties, and are commercially available $[10,11]$. The most common esters are acetate, propionate, and butyrate. Commercial products include cellulose acetate (CA), cellulose acetate propionate (CAP), and cellulose acetate butyrate (CAB).

Essential oils are organophilic materials extracted from plants and contain a variety of different structures $[12,13]$. Because of their fragrance and antimicrobial properties, they are often used in perfume or medicinal formulations $[12,13]$. They have been incorporated occasionally into polymers in order to impart special properties, e.g., for food packaging, personal care, or antimicrobial applications [14-19]. For example, an essential oil can be encased in a packaging film for ease of handling and to minimize bacterial contamination $[20,21]$. An essential oil with an appealing aroma can be 
embedded in a polymer to form an air freshener [13]. An essential oil may serve as a plasticizer in a polymer [22-26]. Of course, it is possible that an essential oil may have more than one of the above functions in a polymer.

With regard to cellulose esters for the food packaging application, it is attractive to incorporate essential oils into the polymer matrix for any of the above functions [22-24]. For these applications, it is useful to conduct a systematic study of common essential oils and observe their interactions with the three common cellulose esters (CA, CAP, and CAB). It is known that the essential oil in a polymer can affect its mechanical and optical properties [22-26]. It is also helpful to evaluate the water vapor permeability of the resulting films because moisture can have an impact on the shelf life of foods [22-26].

The objective of this work was to study the combination of three cellulose esters with nine essential oils (EO), correlate their physical properties with respect to the EO compositions, and observe differences in the physical behaviors of their films. Mechanical testing, water vapor permeability, and opacity were used in the evaluations.

\section{Materials and Methods}

2.1. Materials. Samples of CA (CAS Number 9004-35-7; 39.8 weight $\%$ acetyl, $M_{n} \sim 30,000$ ), CAP (CAS Number 9004-39-1; CAS Number 2.5 weight \% acetyl, 45 weight \% propionyl, $\mathrm{M}_{\mathrm{n}} \sim 25,000$ ), and CAB (CAS Number 9004-36-8; 12-15 weight $\%$ acetyl, 36-40 weight $\%$ butyryl, $\left.M_{n} \sim 30,000\right)$ were acquired from Sigma-Aldrich (St. Louis, MO, USA). Acetone was obtained from Fisher Scientific (Pittsburgh, PA, USA).

The essential oils studied came from key lime (citrus $\times$ aurantiifolia), nutmeg (Myristica fragrans), pimenta berry (Pimenta officinalis), rosemary (Rosmarinus officinalis), petitgrain (Citrus aurantium), coffee (Coffea arabica), and anise (Pimpinella anisum). All of them were acquired from Sigma-Aldrich. Eugenol and trans-cinnamaldehyde were reagent-grade materials also from Sigma-Aldrich. Further information on the essential oils was obtained from SigmaAldrich [27] and from the literature.

2.2. Preparation of Cellulose Ester Films. Each cellulose ester sample (CA, CAP, or CAB) was dissolved in acetone in the ratio of $1: 4(w / w)$ to produce the filmogenic solution. An EO was then added to the solution at an EO/polymer concentration of $20 \%(w / w)$ by stirring, followed by degassing with ultrasound. These concentrations were chosen according to our previous studies of EO/cellulose ester films [22]. In those studies, we found the polymer/acetone solution with $>20 \%$ EO to affect the quality of the film made. The films made without the addition of EO were experimental controls.

All the films were made via the knife casting method. Each filmogenic solution was spread on Teflon-covered glass plates (previously cleaned with isopropanol and then acetone) for film formation. The knife had a gap of $0.27 \mathrm{~mm}$. After the acetone solvent was completely evaporated at room temperature $\left(23 \pm 1^{\circ} \mathrm{C}\right)$, the films were separated from the plates and conditioned in a humidity-controlled room $\left(23 \pm 1^{\circ} \mathrm{C}\right.$ and $\left.50 \pm 5 \% \mathrm{RH}\right)$ for at least 40 hours before mechanical testing. Samples for opacity and water vapor permeation investigation were also held at these conditions.

2.3. Mechanical Properties of the Films. The mechanical properties of each film were determined in a tensile tester (Instron Model 4201 universal testing machine, Norwood, MA, USA) using the ASTM method D882-97 [28]. Three parameters were determined for each sample: Young's modulus (YM, measured in $\mathrm{MPa}$ ), tensile strength (TS, measured in $\mathrm{MPa}$ ), and elongation at break (EB, measured in \%). Prior to measurement, each film was cut into $160 \mathrm{~mm} \times 100 \mathrm{~mm}$ rectangular strips (twin blade cutter, model no. 22-34, Testing Machines, Inc., Newcastle, DE, USA). Film strip samples were then conditioned as mentioned in the preparation step. The initial gauge length of the tensile tester was set at $125 \mathrm{~mm}$, and the jaws were separated at a speed of $12.5 \mathrm{~mm} \mathrm{~min}^{-1}$, using a $1 \mathrm{kN}$ load cell. For each sample, five film strips were tested; the mean and the standard deviation were reported.

For the measurement of film thickness, a MiniTest 3100 gauge acquired from ElektroPhysik (Cologne, Germany) was used. The measurements followed the instructions given by the manufacturer.

2.4. Water Vapor Permeability (WVP). For WVP determination, we used a modified version of ASTM methods [29-32]. The films were cut as circles with a diameter of $60 \mathrm{~mm}$ and positioned on top of a permeation cup (\#5100/1, Elcometer, Inc., Rochester Hills, Michigan) containing a desiccant (previously heated for two hours to $200^{\circ} \mathrm{C}$ and cooled to room temperature). When attached, the exposed area of each film was $10 \mathrm{~cm}^{2}$. The films were placed in a humidity chamber (ESPEC, Hudsonville, Michigan) set at $23^{\circ} \mathrm{C}$ and $50 \%$ relative humidity. The cells were then weighed on the hour daily for 24 hours. The calculations were carried out according to the ASTM methods $[29,30]$.

2.5. Opacity. For film opacity, we followed the method reported by Gontard et al. [33], using a Shimadzu UV2600 spectrophotometer (Norwood, MA, USA) and UV Probe 2.43 software. Each film was cut into $400 \mathrm{~mm}$ x $100 \mathrm{~mm}$ rectangles and attached to the instrument's quartz cuvette. In this way, visible light absorption $(400-800 \mathrm{~nm})$ by the film could be measured. Calibration was achieved by scanning the visible spectrum without a film. The opacity of the film was calculated as the absorbance at $550 \mathrm{~nm}$ divided by the film thickness [34]. The opacity was expressed as $\left(\mathrm{A}-\mathrm{mm}^{-1}\right)$. Triplicate measurements were made for each sample, and the average was reported.

2.6. Statistical Analysis. For mechanical testing, five measurements were made for each tensile sample and the mean and the standard deviation were used. The experiment was conducted using a completely randomized design.

For WVP and opacity, the triplicate data for cellulose ester films and the samples with the nine additives were compared using separate single-factor analysis of variance (ANOVA), one for each cellulose ester (CA, CAP, or CAB), using the Statistical Analysis System SAS 6.0 program [35]. Prior to running ANOVA, Levene's homogeneity of variance 
TABLE 1: Essential oils, their major components, and categorization (Cat.).

\begin{tabular}{lccc}
\hline Essential oil & Major components & Cat. & Refs. \\
\hline Lime & Limonene, $\alpha, \beta$-pinene & 1 & {$[37,42]$} \\
Nutmeg & Limonene, $\alpha, \beta$-pinene, myristicin & 1 & {$[38]$} \\
Eugenol & Eugenol & 2 & {$[37]$} \\
Pimenta berry & Eugenol, methyl eugenol & 3 & {$[41]$} \\
Rosemary & Terpinene, p-cymene, linalool, thymol & 3 & {$[40]$} \\
Petitgrain & Myrcene, pinene, linalool, $\beta$-ocimene, & & \\
Coffee* & geranial, sabinene, neral, citronellol, etc. & $439]$ \\
Anise & Linolenic acid, oleic, stearic & 5 & \\
Cinnamaldehyde & Himachalene, bisabolene & 5 & \\
\hline
\end{tabular}

*Nonterpene part of coffee oil. ${ }^{* *}$ Compositional information given by Sigma-Aldrich.

test was run. If a significant $F$-test value was obtained from an ANOVA at $p \leq 0.05$, then the Differences of Least Squares criterion was used for all pairwise comparisons with a Bonferroni adjustment to control the number of comparisons [36].

\section{Results and Discussion}

For this work, nine essential oils were chosen on the basis of their availability, popular usage, and antimicrobial activity. A complete list of the essential oils and their compositions is given in Table 1. For convenience, these essential oils can be roughly grouped into five categories on the basis of their composition [37-43]. The composition can vary with geography and season. For many essential oils in this study, the major components are terpenes.

(1) limonene/pinenes type: lime, nutmeg

(2) eugenol-based type: eugenol, pimento berry

(3) mixed compositions: rosemary, petitgrain

(4) fatty acid-based type: coffee

(5) others: anise, cinnamaldehyde

Initial compatibility observations with the cellulose esters were made during the EO incorporation. Only the coffee EO film had an oily appearance. It was observed that even though a gauged knife was used to spread the film solutions, the finished film thickness could vary due to concentration and surface tension of the solution, solvent evaporation rate, room temperature, humidity, and other factors. All these factors were kept constant as much as possible.

3.1. Mechanical Properties of the Films. For the packaging film application, the mechanical properties are critical because they reflect film strength, elongation, elasticity, and related end-use properties [44]. The data on Young's modulus (YM), tensile strength (TS), and elongation at break (EB) for CA with and without the added EO's are summarized in Table 2. For CA film by itself, YM was $2519 \mathrm{MPa}$, TS $41 \mathrm{MPa}$, and EB 3\%. YM provides a measure of the stiffness of the film. According to the data given in Table 2, YM gen-
TABLE 2: Film thickness, Young's modulus, tensile strength, and elongation at break of CA films incorporated with $20 \%$ essential oils.

\begin{tabular}{lcccc}
\hline Additive & $\begin{array}{c}\text { Thickness } \\
(\mathrm{mm})\end{array}$ & $\begin{array}{c}\text { YM } \\
(\mathrm{MPa})\end{array}$ & $\begin{array}{c}\text { TS } \\
(\mathrm{MPa})\end{array}$ & $\begin{array}{c}\text { EB } \\
(\%)\end{array}$ \\
\hline None (control) & $0.144 \pm 0.008$ & $2519 \pm 418$ & $41 \pm 2$ & $3 \pm 1$ \\
Lime & $0.178 \pm 0.002$ & $1753 \pm 62$ & $47 \pm 3$ & $24 \pm 3$ \\
Nutmeg & $0.161 \pm 0.003$ & $1834 \pm 81$ & $50 \pm 3$ & $22 \pm 4$ \\
Eugenol & $0.166 \pm 0.022$ & $1670 \pm 71$ & $34 \pm 2$ & $17 \pm 4$ \\
Pimenta berry & $0.172 \pm 0.021$ & $1821 \pm 53$ & $32 \pm 0$ & $6 \pm 1$ \\
Rosemary & $0.167 \pm 0.011$ & $2077 \pm 114$ & $27 \pm 2$ & $1 \pm 0$ \\
Petitgrain & $0.166 \pm 0.007$ & $1753 \pm 71$ & $24 \pm 1$ & $2 \pm 0$ \\
Coffee & $0.167 \pm 0.008$ & $1671 \pm 187$ & $19 \pm 5$ & $1 \pm 0$ \\
Anise & $0.185 \pm 0.028$ & $1830 \pm 216$ & $39 \pm 3$ & $17 \pm 3$ \\
Cinnamaldehyde & $0.161 \pm 0.021$ & $1839 \pm 81$ & $37 \pm 0$ & $15 \pm 4$ \\
\hline
\end{tabular}

erally decreased with the addition of an EO. The striking result is that for films containing five essential oils (lime, nutmeg, eugenol, anise, and trans-cinnamaldehyde), the tensile strength was relatively unaffected but the elongation at break significantly increased. These five essential oils then exhibited a strong plasticizing action on cellulose acetate. Among these essential oils, the best tensile and elongation were shown for lime and nutmeg EO-members of the first category - which have high contents of limonene and pinenes.

The mechanical testing results for CAP and the nine essential oils are shown in Table 3. CAP by itself had YM $2624 \mathrm{MPa}$, TS $34 \mathrm{MPa}$, and EB 1\%. In this case, both the tensile strength and Young's modulus decreased with the addition of EO's, reflecting plasticization by the essential oils. Here again, the essential oils in the first category (lime EO and nutmeg EO) gave the largest increase in elongation. After Category 1, the next strongest plasticizers were the EOs from anise, petitgrain, and rosemary in that order. These are all essential oils from Categories 2 and 3. The essential oil showing the least elongation belonged to Category 4, viz., coffee $\mathrm{EO}$, which has fatty acids as the main components.

The data on YM, TS, and EB for CAB that incorporated various EO's are summarized in Table 4 . CAB by itself had 
TABle 3: Film thickness, Young's modulus, tensile strength, and elongation at break of CAP films incorporated with $20 \%$ essential oils.

\begin{tabular}{lcccc}
\hline Additive & $\begin{array}{c}\text { Thickness } \\
(\mathrm{mm})\end{array}$ & $\begin{array}{c}\text { YM } \\
(\mathrm{MPa})\end{array}$ & $\begin{array}{c}\text { TS } \\
(\mathrm{MPa})\end{array}$ & $\begin{array}{c}\text { EB } \\
(\%)\end{array}$ \\
\hline None (control) & $0.148 \pm 0.002$ & $2624 \pm 151$ & $34 \pm 2$ & $1 \pm 0$ \\
Lime & $0.163 \pm 0.031$ & $1187 \pm 86$ & $27 \pm 1$ & $21 \pm 3$ \\
Nutmeg & $0.168 \pm 0.004$ & $1225 \pm 30$ & $28 \pm 1$ & $27 \pm 3$ \\
Eugenol & $0.182 \pm 0.026$ & $935 \pm 40$ & $19 \pm 1$ & $6 \pm 1$ \\
Pimenta berry & $0.148 \pm 0.026$ & $934 \pm 78$ & $18 \pm 1$ & $8 \pm 1$ \\
Rosemary & $0.174 \pm 0.035$ & $1330 \pm 51$ & $28 \pm 1$ & $11 \pm 3$ \\
Petitgrain & $0.139 \pm 0.028$ & $1204 \pm 54$ & $25 \pm 1$ & $12 \pm 2$ \\
Coffee & $0.195 \pm 0.025$ & $1163 \pm 203$ & $2 \pm 1$ & $0 \pm 0$ \\
Anise & $0.200 \pm 0.016$ & $1203 \pm 28$ & $25 \pm 1$ & $18 \pm 2$ \\
Cinnamaldehyde & $0.165 \pm 0.018$ & $1011 \pm 59$ & $23 \pm 1$ & $8 \pm 2$ \\
\hline
\end{tabular}

the lowest TS $(27 \mathrm{MPa})$ and YM $(2077 \mathrm{MPa})$, relative to CA and CAP. Again, the tensile and the Young's modulus decreased with the addition of EO's, but the elongation observed for the CAP series was rather low (1-17\%), relative to CA and CAP. The best plasticizers were again the ones in Category 1: lime EO and nutmeg EO. The EO's in Categories 2 and 3 were in the middle. The EO in Category 4 was again the weakest plasticizer, joined here by rosemary EO.

These observations are mostly in line with other studies where the incorporation of essential oils in a polymer was found to increase elongation $[16,17,22,23,45]$. The only exception was the study by Ahmad et al. [19], who observed a slight decrease in EB when bergamot and lemongrass EO were incorporated into gelatin films. Likewise, the decrease in Young's modulus (YM) with the addition of EO was reported by Bastos et al. [22] and Tongnuanchan et al. [18]. The reduction in TS with the addition of EO's was reported earlier by Bastos et al. [22] and Espitia et al. [23] in cellulose ester films and by Benavides et al. [16] in alginate films, but a contrary trend was found for the incorporation of olive oil into chitosan films [46].

In Figure 1, the changes in the tensile strength relative to the polymer control $(\Delta \mathrm{TS})$ versus the change in $\mathrm{EB}$ relative to the polymer control $(\triangle \mathrm{EB})$ for all three cellulosic polymers are displayed. In all three plots, there is a trend of decreasing tensile strength as the elongation increases. Thus, the addition of an essential oil to cellulose ester film produces a trade-off in tensile strength versus elongation. However, some optimal situations can be found. For example, in the case of cellulose acetate (Figure 1(a)), the addition of lime and nutmeg essential oils gives a larger tensile strength and elongation. Moreover, for cellulose acetate propionate (Figure 1(b)), the curve is almost flat for 5 essential oils with a loss in tensile strength of about 6-10 MPa but with a gain in $\mathrm{EAB}$ of $10-25 \%$.

In contrast to TS, the decrease in Young's modulus relative to the polymer control is roughly the same for all the essential oils added in a given cellulose ester. Thus, when plotted as a function of $\triangle \mathrm{EB}$, the $\triangle \mathrm{YM}$ curves are almost horizontal with no clear trends (figures not shown). Thus, the
TABLE 4: Film thickness, Young's modulus, tensile strength, and elongation at break of CAB films incorporated with $20 \%$ essential oils.

\begin{tabular}{lcccc}
\hline Additive & $\begin{array}{c}\text { Thickness } \\
(\mathrm{mm})\end{array}$ & $\begin{array}{c}\text { YM } \\
(\mathrm{MPa})\end{array}$ & $\begin{array}{c}\text { TS } \\
(\mathrm{MPa})\end{array}$ & $\begin{array}{c}\text { EB } \\
(\%)\end{array}$ \\
\hline None (control) & $0.162 \pm 0.014$ & $2077 \pm 82$ & $27 \pm 5$ & $1 \pm 0$ \\
Lime & $0.178 \pm 0.026$ & $1104 \pm 68$ & $25 \pm 1$ & $8 \pm 1$ \\
Nutmeg & $0.166 \pm 0.003$ & $1050 \pm 16$ & $23 \pm 0$ & $7 \pm 1$ \\
Eugenol & $0.177 \pm 0.019$ & $776 \pm 53$ & $14 \pm 1$ & $3 \pm 0$ \\
Pimenta berry & $0.088 \pm 0.003$ & $882 \pm 14$ & $14 \pm 0$ & $2 \pm 0$ \\
Rosemary & $0.133 \pm 0.014$ & $1287 \pm 47$ & $12 \pm 1$ & $1 \pm 0$ \\
Petitgrain & $0.187 \pm 0.031$ & $925 \pm 38$ & $15 \pm 1$ & $2 \pm 0$ \\
Coffee & $0.185 \pm 0.018$ & $1240 \pm 57$ & $13 \pm 2$ & $1 \pm 0$ \\
Anise & $0.145 \pm 0.016$ & $1171 \pm 50$ & $19 \pm 1$ & $2 \pm 0$ \\
Cinnamaldehyde & $0.159 \pm 0.029$ & $1106 \pm 101$ & $17 \pm 2$ & $2 \pm 0$ \\
\hline
\end{tabular}

addition of the nine essential oils to the cellulose ester films decreases the rigidity of the films approximately to the same extent. Because the TS and the EB are measured when the film breaks, whereas YM is measured by the initial slope of the stress-strain curve, the different behavior of TS and YM is not surprising.

3.2. Water Vapor Permeability. The water vapor permeability (WVP) data for CA, CAP, and CAB with and without EO's are shown in Table 5. For most films with EO's, there were significant differences $(p<0.05)$ compared to the control films, indicating that the addition of the $\mathrm{EO}$ caused a decrease in the WVP. In general, CAP films had the highest average permeability (2.52 units), followed by CA films (1.87 units), and then $\mathrm{CAB}$ films (1.75 units). All CAP films were more permeable than the two other cellulose ester EO films except for CA control, CA coffee EO, and CA rosemary EO.

In the CA series, there were two samples that were similar in WVP to the control (rosemary EO, coffee EO). In the CAP and $\mathrm{CAB}$ series, the permeabilities for three essential oils were similar to the control (rosemary, petitgrain, and lime). In the $\mathrm{CAB}$ series, the only treatment with significantly less WVP than the control was eugenol.

3.3. Opacity. The opacity data for CA, CAP, and CAB films with and without EO's are given in Table 6. It appears that for CA and CAP, EO incorporation decreased the opacity of the films. As a whole, CAP films seemed to be the most transparent (averaging to $137 \mathrm{~A}-\mathrm{mm}^{-1}$ ). The films with eugenol, anise EO, and pimenta berry EO showed the most transparency, and the film with coffee EO was the least transparent. Specifically, a few significant opacity reductions (about $50 \%$ or more) may be mentioned, e.g., CA eugenol, CAP eugenol, $\mathrm{CAP}$ rosemary $\mathrm{EO}$, and $\mathrm{CAB}$ lime $\mathrm{EO}$. The ones with significant opacity enhancements included CA petitgrain EO, CA coffee EO, CAP coffee EO, and CAB coffee EO.

Opacity is likely influenced by the incompatibility of the essential oil with the cellulose ester, the differences in the refractive indices of the oil and the continuous phases, and the size and concentration of the dispersed oil. For food 


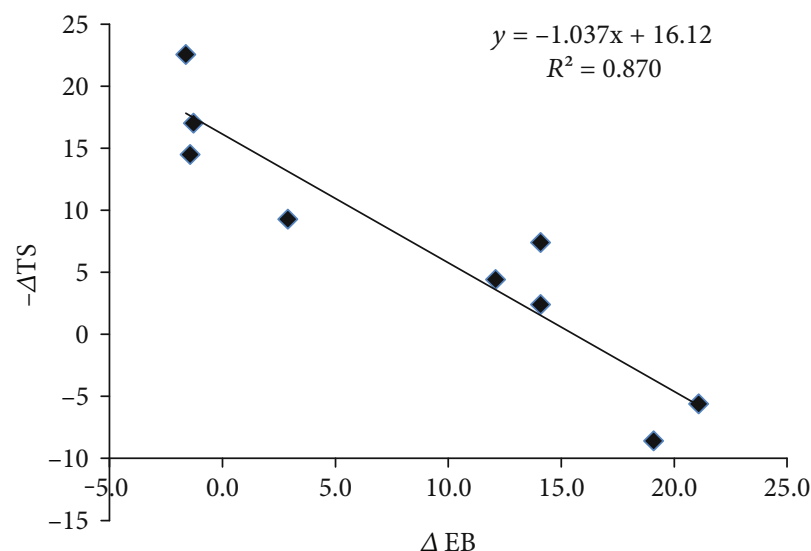

(a)

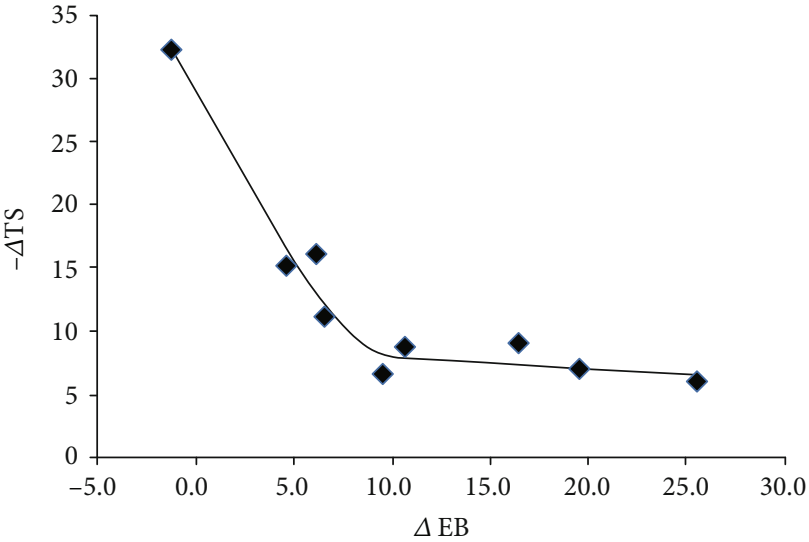

(b)

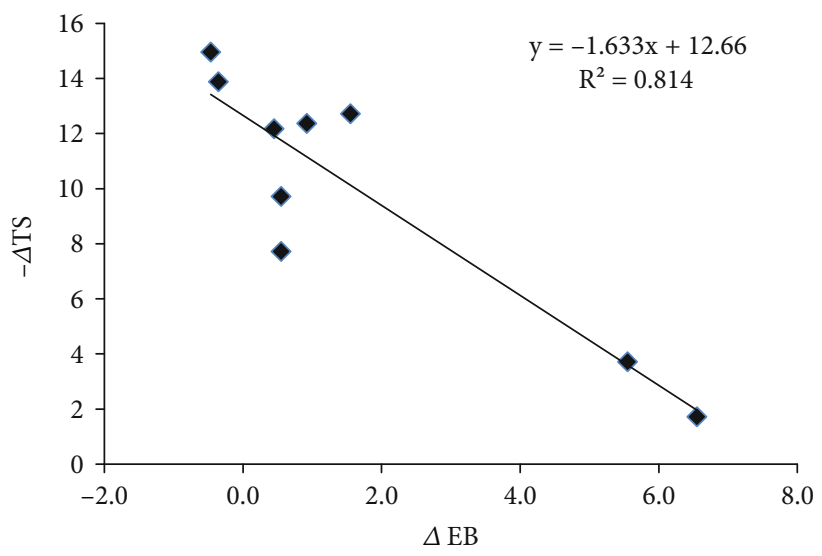

(c)

FIGURE 1: Difference in tensile strength between polymer-EO film and polymer control ( $\Delta \mathrm{TS})$ versus difference in elongation at break between polymer-EO film and polymer control $(\triangle \mathrm{EB})$. (a) CA (data fitted to a linear equation), (b) CAP (data showing an asymptotic horizontal behavior), and (c) CAB (data fitted to a linear equation).

TABLE 5: Water vapor permeability data (in units of $\mathrm{mg}-\mathrm{m}-\mathrm{kPa}-\mathrm{h}-\mathrm{m}^{2}$ ) for cellulose ester-EO films.

\begin{tabular}{lccc}
\hline Additive & CA $^{*}$ & CAP $^{*}$ & CAB $^{*}$ \\
\hline None (control) & $2.69 \mathrm{a}$ & $2.74 \mathrm{a}, \mathrm{b}, \mathrm{c}$ & $1.87 \mathrm{a}, \mathrm{b}, \mathrm{c}, \mathrm{d}$ \\
Lime & $1.97 \mathrm{~b}$ & $2.62 \mathrm{a}, \mathrm{b}, \mathrm{c}, \mathrm{d}$ & $2.04 \mathrm{a}, \mathrm{b}$ \\
Nutmeg & $1.82 \mathrm{~b}, \mathrm{c}$ & $2.53 \mathrm{~b}, \mathrm{c}, \mathrm{d}, \mathrm{e}$ & $1.91 \mathrm{a}, \mathrm{b}, \mathrm{c}$ \\
Eugenol & $1.17 \mathrm{~d}$ & $2.28 \mathrm{c}, \mathrm{d}, \mathrm{e}$ & $1.29 \mathrm{e}$ \\
Pimenta berry & $1.27 \mathrm{~d}$ & $2.25 \mathrm{~d}, \mathrm{e}$ & $1.42 \mathrm{~d}, \mathrm{e}$ \\
Rosemary & $2.44 \mathrm{a}$ & $3.03 \mathrm{a}$ & $2.15 \mathrm{a}, \mathrm{b}$ \\
Petitgrain & $1.88 \mathrm{~b}, \mathrm{c}$ & $2.8 \mathrm{a}, \mathrm{b}$ & $2.16 \mathrm{a}$ \\
Coffee & $2.49 \mathrm{a}$ & $2.33 \mathrm{c}, \mathrm{d}, \mathrm{e}$ & $1.47 \mathrm{c}, \mathrm{d}, \mathrm{e}$ \\
Anise & $1.53 \mathrm{~b}, \mathrm{c}, \mathrm{d}$ & $2.48 \mathrm{~b}, \mathrm{c}, \mathrm{d}, \mathrm{e}$ & $1.53 \mathrm{c}, \mathrm{d}, \mathrm{e}$ \\
Cinnamaldehyde & $1.47 \mathrm{c}, \mathrm{d}$ & $2.12 \mathrm{e}$ & $1.68 \mathrm{~b}, \mathrm{c}, \mathrm{d}, \mathrm{e}$ \\
Average & 1.87 & 2.52 & 1.75 \\
\hline
\end{tabular}

${ }^{*}$ Values within a column (for each cellulose ester) sharing the same letter(s) are not significantly different based on differences of least squares means at $p \leq 0.05$ using a Bonferroni adjustment.
TABLE 6: Opacity data (in units of A- $\mathrm{mm}^{-1}$ ) for cellulose ester-EO films.

\begin{tabular}{lccc}
\hline Additive & CA* $^{*}$ & CAP $^{*}$ & CAB $^{*}$ \\
\hline None (control) & $90 \mathrm{~b}$ & $121 \mathrm{~b}$ & $199 \mathrm{~b}, \mathrm{c}$ \\
Lime & $211 \mathrm{a}$ & $292 \mathrm{a}$ & $65 \mathrm{f}$ \\
Nutmeg & $194 \mathrm{a}$ & $80 \mathrm{~b}, \mathrm{c}, \mathrm{d}$ & $111 \mathrm{e}$ \\
Eugenol & $58 \mathrm{~b}$ & $50 \mathrm{~d}$ & $122 \mathrm{e}$ \\
Pimenta berry & $91 \mathrm{~b}$ & $83 \mathrm{~b}, \mathrm{c}$ & $181 \mathrm{c}, \mathrm{d}$ \\
Rosemary & $204 \mathrm{a}$ & $64 \mathrm{c}, \mathrm{d}$ & $152 \mathrm{~d}, \mathrm{e}$ \\
Petitgrain & $403 \mathrm{a}$ & $85 \mathrm{~b}, \mathrm{c}$ & $173 \mathrm{c}, \mathrm{d}$ \\
Coffee & $415 \mathrm{a}$ & $394 \mathrm{a}$ & $449 \mathrm{a}$ \\
Anise & $81 \mathrm{~b}$ & $76 \mathrm{~b}, \mathrm{c}, \mathrm{d}$ & $127 \mathrm{e}$ \\
Cinnamaldehyde & $103 \mathrm{~b}$ & $121 \mathrm{~b}$ & $237 \mathrm{~b}$ \\
Average & 145 & 137 & 182 \\
\hline
\end{tabular}

*Values within a column (for each cellulose ester) sharing the same letter(s) are not significantly different based on differences of least squares means at $p \leq 0.05$ using a Bonferroni adjustment. 
packaging, sometimes a decreased opacity is desired because the food item can be more easily observed through the package. However, for food items that can undergo oxidation with sunlight, an increased opacity is actually better for food preservation. Thus, the ability to change opacity with a different choice of an essential oil (as shown in this study) can be a benefit in practice.

3.4. Comments. In this work, nine essential oils were embedded at $20 \%(w / w)$ in three cellulose ester films and studies made of several physical and mechanical properties of the resulting materials. The mechanical testing results suggested that the essential oils interacted with the polymers like plasticizers, leading to some reductions in tensile strength and Young's modulus but enhancements in elongation at break. The essential oils studied could be approximately grouped into five categories, depending on chemical composition. Category 1 (those containing limonene and pinenes) showed the largest elongation, and Category 4 (those containing fatty acids) gave the least elongation. The fact that essential oils in Category 1 can serve as effective plasticizers is of interest because most of the current plasticizers for cellulose esters are all small-molecule esters. Thus, the present results suggest that terpene and terpene-like chemical compounds may be suitable plasticizers for cellulose esters. In this connection, it may be noted that the first cellulosic plastic (celluloid, a thermoplastic) was composed of nitrocellulose and camphor [47].

It may also be noted that the tensile elongation at break is inversely proportional to the brittleness of a material. Thus, the addition of EO's reduces the brittleness of cellulose esters. A good discussion of brittleness and an equation giving the function of brittleness versus elongation have been given in an earlier book by Brostow and Hagg Lobland [48].

Furthermore, the addition of most of the essential oils to cellulose ester films caused a decrease in the water vapor permeability due to the hydrophobic nature of the oil. This can be an advantage if we want to preserve water-sensitive foods or materials. Moreover, some changes in opacity were observed with EO addition. This feature could be customized for the particular need of the food product being packaged. Although not emphasized in this study, the essential oils are also known for their antimicrobial properties [37, 49]. In general, films that reduce microbial growth can preserve food longer.

Thus, the use of an essential oil in cellulose ester films for food packaging has at least four valuable characteristics: improved film flexibility, decreased water vapor permeability, variable opacity, and antimicrobial activity. The combinations of three cellulose esters and nine essential oils studied in this work exhibited a range of physical and mechanical properties. Depending on a specific application, a particular polymer/EO combination can be used to give the optimal performance. For future product development, perhaps these combinations may be taken into consideration in food production and preservation.

\section{Conclusions}

In recent years, there has been a great deal of interest in using essential oils directly as natural additives into foods for shelf- life extension due to the risk of using synthetic preservatives [50] and in adding essential oils to bio-based food packaging systems to modify the physical properties of the packaging films [14-24]. Cellulosic esters have been studied as biobased film materials because of their properties [22, 23], but in order to proceed further with the cellulose ester/essential oil systems, more data are needed to assess the scope and the potential of the various combinations. The current study is aimed at providing this information, with three cellulose esters (CA, CAP, and CAB) and nine essential oils. The results suggest that there is sufficient diversity in the nature of the cellulose ester and essential oils such that different film properties (mechanical, water vapor permeability, and opacity) can be achieved by choosing a suitable combination of film components. This is a promising finding and indicates that the cellulose ester/essential oil system can be seriously considered for future product development of bio-based food packaging.

In addition to food packaging applications, other uses of essential oil-embedded cellulose esters may perhaps be found in biodegradable plastics [51], e.g., as films that cover the surface of cultivated fields to reduce moisture loss and as disposable plastic wares for use in airplanes, hotels, and hospitals.

\section{Data Availability}

The data used to support the findings of this study are available from the corresponding authors upon request.

\section{Disclosure}

Mention of trade names or commercial products in this publication is solely for the purpose of providing specific information and does not imply recommendation or endorsement by the U.S. Department of Agriculture. USDA is an equal opportunity provider and employer.

\section{Conflicts of Interest}

The authors declare that there is no conflict of interest regarding the publication of this paper.

\section{Acknowledgments}

Atanu Biswas and Roselayne Ferro Furtado thank the Brazilian National Council for Scientific and Technological Development (CNPq, process no. 405506/2013-9) for support of this work through the Science without Borders program. The authors would like to thank Dr. Will Hays and Deb Palmquist for technical assistance and Dr. Steven Vaughn for the trans-cinnamaldehyde sample.

\section{References}

[1] M. J. Kirwan and J. W. Strawbridge, "Plastics in food packaging," in Food Packaging Technology, R. Coles, D. McDowell, and M. J. Kirwin, Eds., pp. 174-240, Blackwell, Oxford, UK, 2003.

[2] G. L. Robertson, Food Packaging: Principles and Practice, CRC Press, Boca Raton, FL, USA, 3rd edition, 2012. 
[3] K. Marsh and B. Bugusu, "Food packaging_roles, materials, and environmental issues," Journal of Food Science, vol. 72, no. 3, pp. R39-R55, 2007.

[4] C. Y. Barlow and D. C. Morgan, "Polymer film packaging for food: an environmental assessment," Resources, Conservation and Recycling, vol. 78, pp. 74-80, 2013.

[5] V. Siracusa, P. Rocculi, S. Romani, and M. D. Rosa, "Biodegradable polymers for food packaging: a review," Trends in Food Science and Technology, vol. 19, no. 12, pp. 634-643, 2008.

[6] S. Guilbert, B. Cuq, and N. Gontard, "Recent innovations in edible and/or biodegradable packaging materials," Food Additives and Contaminants, vol. 14, no. 6-7, pp. 741-751, 1997.

[7] J. M. Krochta and C. Mulder-Johnston, "Edible and biodegradable polymer films: challenges and opportunities," Food Technology, vol. 51, pp. 61-74, 1997.

[8] J. M. Fang, P. A. Fowler, C. Escrig, R. Gonzalez, J. A. Costa, and L. Chamudis, "Development of biodegradable laminate films derived from naturally occurring carbohydrate polymers," Carbohydrate Polymers, vol. 60, no. 1, pp. 39-42, 2005.

[9] M. Avella, J. J. De Vlieger, M. E. Errico, S. Fischer, P. Vacca, and M. G. Volpe, "Biodegradable starch/clay nanocomposite films for food packaging applications," Food Chemistry, vol. 93, no. 3, pp. 467-474, 2005.

[10] T. Heinze, T. Liebert, and A. Koschella, Esterification of Polysaccharides, Springer, Berlin, Heidelberg, New York, 2006.

[11] http://www.eastman.com/Markets/Coatings/ TechnologySolutions/Pages/EASTMAN_Cellulose_Esters .aspx.

[12] K. H. C. Baser and G. Buchbauer, Handbook of Essential Oils: Science, Technology, and Applications, CRC Press, Boca Raton, FL, USA, 2nd edition, 2016.

[13] V. A. Worwood, The Complete Book of Essential Oils and Aromatherapy, New World Library, Novato, CA, USA, 1991.

[14] M. Ghasemlou, N. Aliheidari, R. Fahmi et al., "Physical, mechanical and barrier properties of corn starch films incorporated with plant essential oils," Carbohydrate Polymers, vol. 98, no. 1, pp. 1117-1126, 2013.

[15] M. A. Rojas-Graü, R. J. Avena-Bustillos, C. Olsen et al., "Effects of plant essential oils and oil compounds on mechanical, barrier and antimicrobial properties of alginate-apple puree edible films," Journal of Food Engineering, vol. 81, no. 3, pp. 634-641, 2007.

[16] S. Benavides, R. Villalobos-Carvajal, and J. E. Reyes, "Physical, mechanical and antibacterial properties of alginate film: effect of the crosslinking degree and oregano essential oil concentration," Journal of Food Engineering, vol. 110, no. 2, pp. 232-239, 2012.

[17] A. Aguirre, R. Borneo, and A. E. León, “Antimicrobial, mechanical and barrier properties of triticale protein films incorporated with oregano essential oil," Food Bioscience, vol. 1, pp. 2-9, 2013.

[18] P. Tongnuanchan, S. Benjakul, and T. Prodpran, "Physicochemical properties, morphology and antioxidant activity of film from fish skin gelatin incorporated with root essential oils," Journal of Food Engineering, vol. 117, no. 3, pp. 350360, 2013.

[19] M. Ahmad, S. Benjakul, T. Prodpran, and T. W. Agustini, "Physico-mechanical and antimicrobial properties of gelatin film from the skin of unicorn leatherjacket incorporated with essential oils," Food Hydrocolloids, vol. 28, no. 1, pp. 189199, 2012.
[20] N. F. F. Soares, W. A. Silva, A. C. S. Pires, G. P. Camilloto, and P. S. Silva, "Novos desenvolvimentos e aplicações em embalagens de alimentos," Revista Ceres, vol. 56, pp. 370-378, 2009.

[21] E. Kristo, K. P. Koutsoumanis, and C. G. Biliaderis, "Thermal, mechanical and water vapor barrier properties of sodium caseinate films containing antimicrobials and their inhibitory action on Listeria monocytogenes," Food Hydrocolloids, vol. 22, no. 3, pp. 373-386, 2008.

[22] M. do Socorro Rocha Bastos, L. da Silva Laurentino, K. M. Canuto et al., "Physical and mechanical testing of essential oil-embedded cellulose ester films," Polymer Testing, vol. 49, pp. 156-161, 2016.

[23] P. J. P. Espitia, N. D. F. F. Soares, L. C. M. Botti, and W. A. Silva, "Effect of essential Oils in the properties of cellulosic active packaging," Macromolecular Symposia, vol. 299-300, no. 1, pp. 199-205, 2011.

[24] V. Coma, "Bioactive packaging technologies for extended shelf life of meat-based products," Meat Science, vol. 78, no. 1-2, pp. 90-103, 2008.

[25] P. Appendini and J. H. Hotchkiss, "Review of antimicrobial food packaging," Innovative Food Science and Emerging Technologies, vol. 3, no. 2, pp. 113-126, 2002.

[26] T. H. McHugh and J. M. Krochta, "Sorbitol vs glycerolplasticized whey protein edible films: integrated oxygen permeability and tensile property evaluation," Journal of Agricultural and Food Chemistry, vol. 42, no. 4, pp. 841-845, 1994.

[27] http://www.sigmaaldrich.com/united-states.html.

[28] American Society for Testing and Materials, Standard test method for tensile properties of thin plastic sheeting, ASTM, 2001.

[29] American Society for Testing and Materials, Standard test methods for water vapor transmission of materials, ASTM, 2000.

[30] American Society for Testing and Materials, Standard test methods for water vapor transmission of organic coating films, ASTM, 2013.

[31] R. Shogren, "Water vapor permeability of biodegradable polymers," Journal of Environmental Polymer Degradation, vol. 5, no. 2, pp. 91-95, 1997.

[32] B. Biquet and T. P. Labuza, "Evaluation of the moisture permeability characteristics of chocolate films as an edible moisture barrier," Journal of Food Science, vol. 53, no. 4, pp. 989-998, 1988.

[33] N. Gontard, S. Guilbert, and J. L. Cuq, "Edible wheat gluten films: influence of the main process variables on film properties using response surface methodology," Journal of Food Science, vol. 57, no. 1, pp. 190-195, 1992.

[34] A. Farhan and N. M. Hani, "Characterization of edible packaging films based on semi-refined kappa- carrageenan plasticized with glycerol and sorbitol," Food Hydrocolloids, vol. 64, pp. 48-58, 2017.

[35] SAS Institute, Inc, SAS User's Guide, Version 9.1, SAS Institute, Cary, NC, 2006.

[36] S. L. Weinberg and S. Knapp, Data Analysis for the Behavioral Sciences Using SPSS, Cambridge Univ, Press, Cambridge, UK, 2002.

[37] K. A. Hammer, C. F. Carson, and T. V. Riley, "Antimicrobial activity of essential oils and other plant extracts," Journal of Applied Microbiology, vol. 86, no. 6, pp. 985-990, 1999.

[38] Muchtaridi, A. Subarnas, A. Apriyantono, and R. Mustarichie, "Identification of compounds in the essential oil of nutmeg 
seeds (Myristica fragrans Houtt.) that inhibit locomotor activity in mice," International Journal of Molecular Sciences, vol. 11, no. 11, pp. 4771-4781, 2010.

[39] L. Mondello, G. Dugo, P. Dugo, and K. D. Bartle, "Italian Citrus Petitgrain oils. Part I. Composition of bitter orange petitgrain oil," Journal of Essential Oil Research, vol. 8, no. 6, pp. 597-609, 1996.

[40] W. Wang, N. Wu, Y. G. Zu, and Y. J. Fu, “Antioxidative activity of Rosmarinus officinalis L. essential oil compared to its main components," Food Chemistry, vol. 108, no. 3, pp. 1019-1022, 2008.

[41] J. Abaul, P. Bourgeois, and J. M. Bessiere, "Chemical composition of the essential oils of chemotypes of Pimenta racemosa var. racemosa (P. Miller) J. W. Moore (Bois d'Inde) of Guadeloupe (F.W.I.)," Flavour and Fragrance Journal, vol. 10, no. 5, pp. 319-321, 1995.

[42] A. C. Atti-Santos, M. Rossato, L. A. Serafini, E. Cassel, and P. Moyna, "Extraction of essential oils from lime (Citrus latifolia Tanaka) by hydrodistillation and supercritical carbon dioxide," Brazilian Archives of Biology and Technology, vol. 48, no. 1, pp. 155-160, 2005.

[43] L. S. Oliveira, A. S. Franca, J. C. F. Mendonca, and M. C. Barros-Junior, "Proximate composition and fatty acids profile of green and roasted defective coffee beans," LWT - Food Science and Technology, vol. 39, no. 3, pp. 235-239, 2006.

[44] C. H. Chen, W. S. Kuo, and L. S. Lai, "Effect of surfactants on water barrier and physical properties of tapioca starch/decolorized hsian-tsao leaf gum films," Food Hydrocolloids, vol. 23, no. 3, pp. 714-721, 2009.

[45] A. R. F. e Moraes, L. E. R. Gouveia, N. de Fátima Ferreira Soares, M. M. de Souza Santos, and M. P. J. C. Gonçalves, "Desenvolvimento e avaliação de filme antimicrobiano na conservação de manteiga," Ciência e Tecnologia de Alimentos, vol. 27, pp. 33-36, 2007.

[46] M. Pereda, G. Amica, and N. E. Marcovich, "Development and characterization of edible chitosan/olive oil emulsion films," Carbohydrate Polymers, vol. 87, no. 2, pp. 1318-1325, 2012.

[47] G. R. Filho, D. S. Monteiro, C. da Silva Meireles et al., "Synthesis and characterization of cellulose acetate produced from recycled newspaper," Carbohydrate Polymers, vol. 73, no. 1, pp. 74-82, 2008.

[48] W. Brostow and H. E. Hagg Lobland, Materials: Introduction and Applications, John Wiley \& Sons, Hoboken, NJ, USA, 2017.

[49] S. Pattnaik, V. R. Subramanyam, and C. Kole, "Antibacterial and antifungal activity of ten essential oils in vitro," Microbios, vol. 86, no. 349, pp. 237-246, 1996.

[50] J. Fernández-López and M. Viuda-Martos, "Introduction to the special issue: application of essential oils in food systems," Foods (Basel, Switzerland), vol. 7, no. 4, p. 56, 2018.

[51] K. J. Edgar, C. M. Buchanan, J. S. Debenham et al., "Advances in cellulose ester performance and application," Progress in Polymer Science, vol. 26, no. 9, pp. 1605-1688, 2001. 